\title{
Direct effects of acidic wet deposition on photosynthesis and stomatal conductance of two Populus clones ( $P$. cv. Beaupré and P. cv. Robusta)
}

\author{
C. Martens, K. Landuydt and I. Impens
}

Department of Biology, University of Antwerp (U.I.A.), Universiteitsplein 1, B-2610 Wilrijk (Antwerpen), Belgium

\section{Introduction}

Poplar, characterized by rapid growth, is an important source of fiber products in Belgium (Steenackers, 1982). Growth reduction due to acidic precipitation may have important economic consequences. Poplar is known to be sensitive to gaseous air pollutants (e.g., leaf damage) (Freer-Smith, 1984; Wang et al,, 1986). In this study, direct effects of acidic precipitation on leaf gas exchange were determined for two clones.

\section{Materials and Methods}

Poplar cuttings (Populus sp. cv. Beaupré and cv. Robusta) were grown in a greenhouse in plastic containers (11.2 I) and exposed to simulated acidic rain of $\mathrm{pH} 4.0$ or to a control solution of $\mathrm{pH} 5.6,3$ times a week. The soil was covered with a plastic hood to avoid indirect effects of acid precipitation.

The interactive effects of leaf age and exposure to acid rain on leaf gas exchange were studied by measuring net photosynthetic rate and stomatal conductance at different leaf ages (i.e., different leaf plastochron index (LPI)) Measurements were obtained at light saturation, using an artificial light source (>800 $\mu \mathrm{E} \cdot \mathrm{m}^{-2} \cdot \mathrm{s}^{-1}$ ): PNsat and $g_{\mathrm{s}}$ sat. Light saturated net photosynthesis data were obtained using a portable gas exchange system, as described by Ceulemans et al. (1986). Stomatal conductances were measured with an automatic water vapor diffusion porometer.

Mean values of 6-12 measurements of each LPI were calculated with $95 \%$ confidence limits. Non-overlapping limits indicate significant differences between the two $\mathrm{pH}$ treatments.

\section{Results}

Net photosynthesis was decreased by acid rain ( $\mathrm{pH} \mathrm{4.0)}$ in cv. Beaupré (Fig. 1). The differences compared to the control group were highly significant for cv. Beaupré but not for cv. Robusta. These differences were greatest at optimal leaf age (LPI 9 for cv. Beaupré). A reduction (in PNsat) of $28.2 \%$ was recorded for $\mathrm{cv}$. Beaupré.

Stomatal conductances ( $\left.g_{s} s a t\right)$ were calculated from stomatal resistance mea- 
cV. ROBUSTA

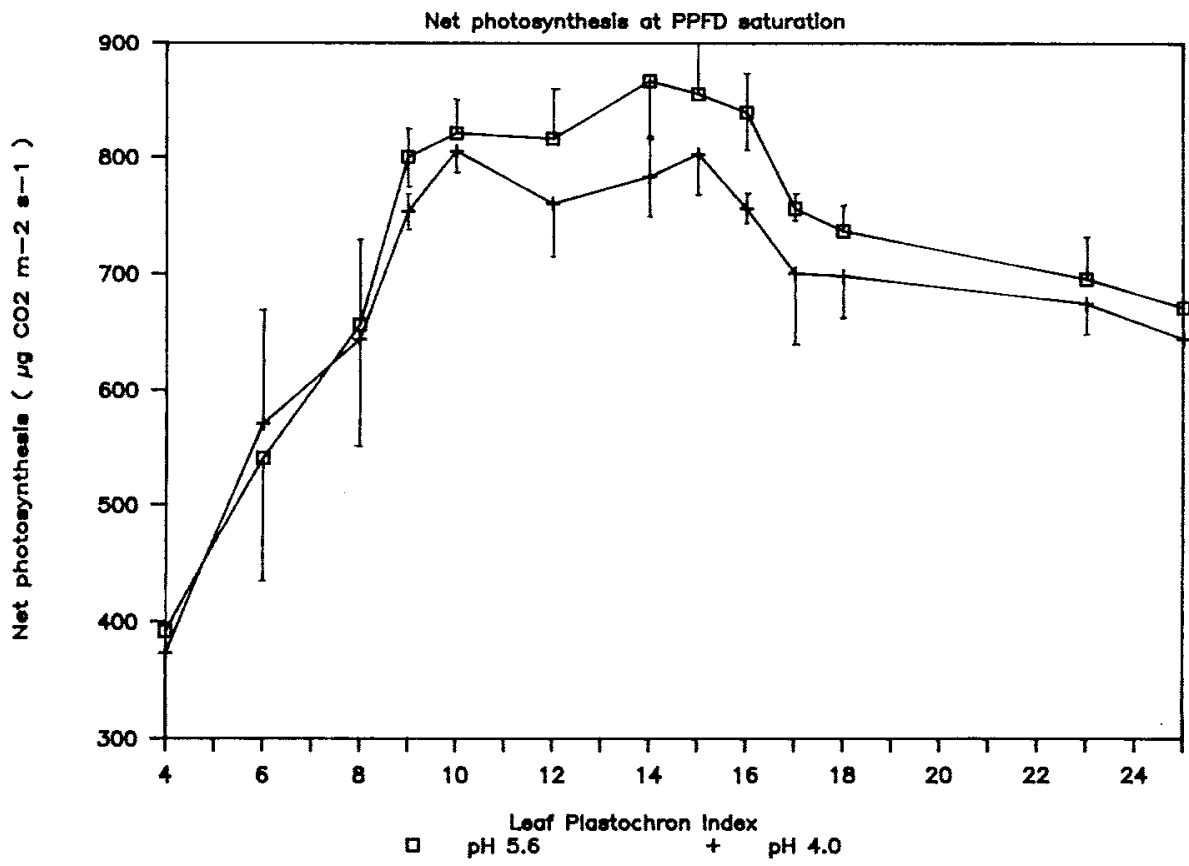

cV. BEAUPRE

Net photosynthesis at PPFD soturation

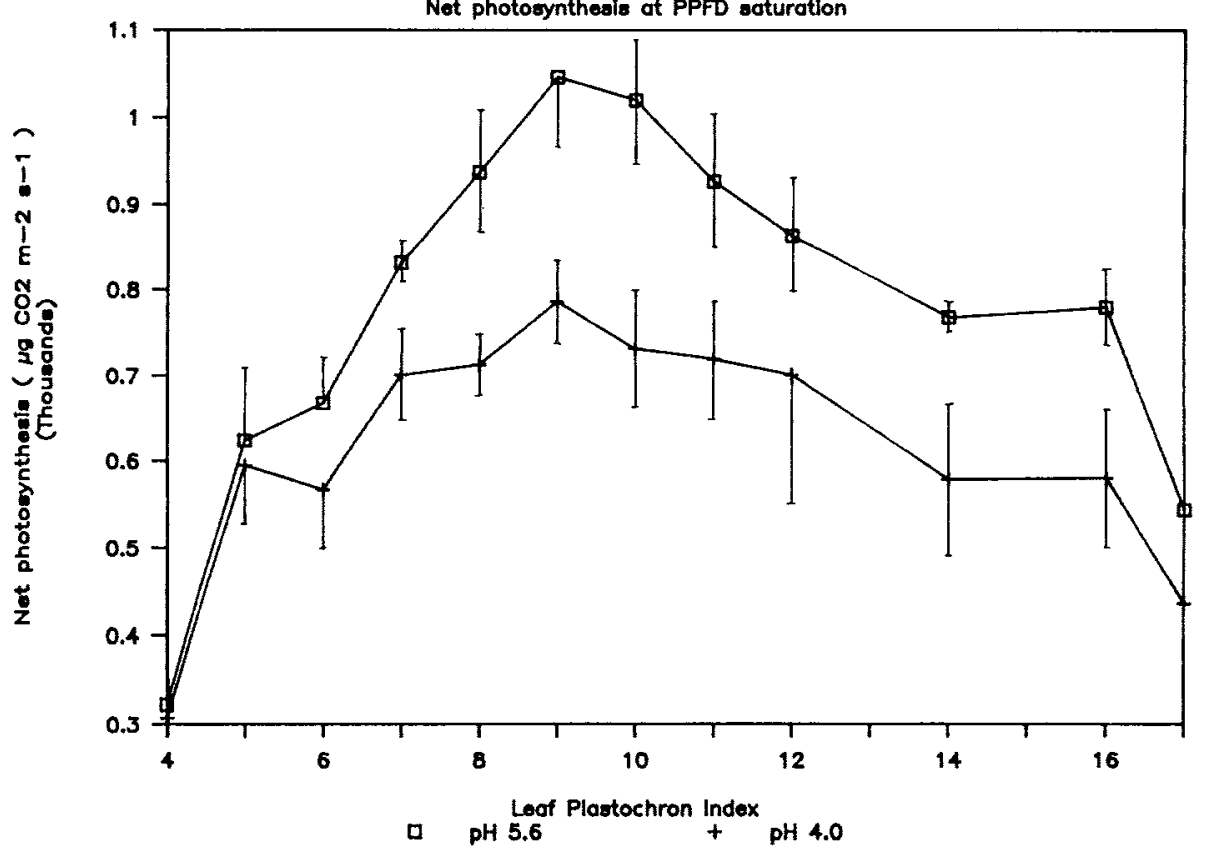

Fig. 1. Net photosynthesis, PNsat, at different leaf ages (LPI) for both pH groups. Bar: $95 \%$ confidence limit. 
cV. BEAUPRE

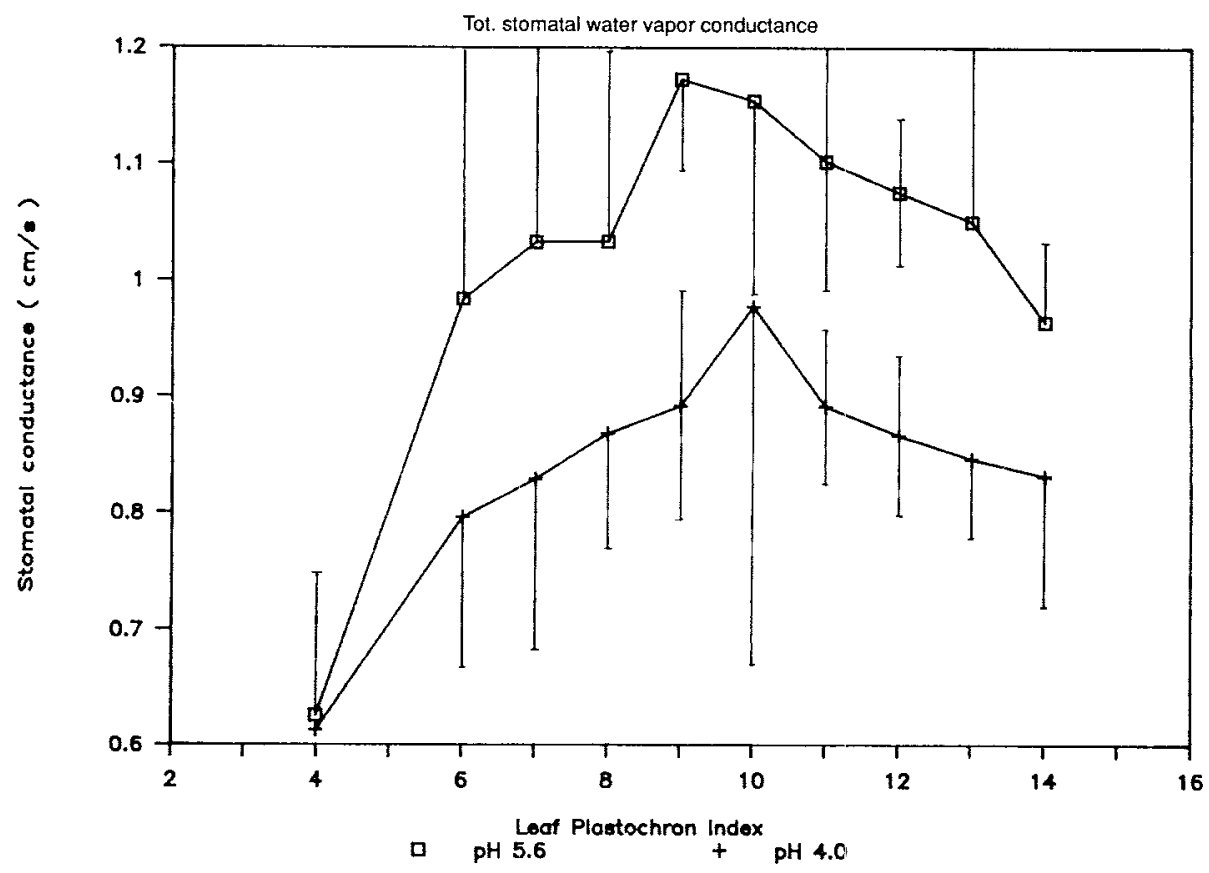

CV.ROBUSTA

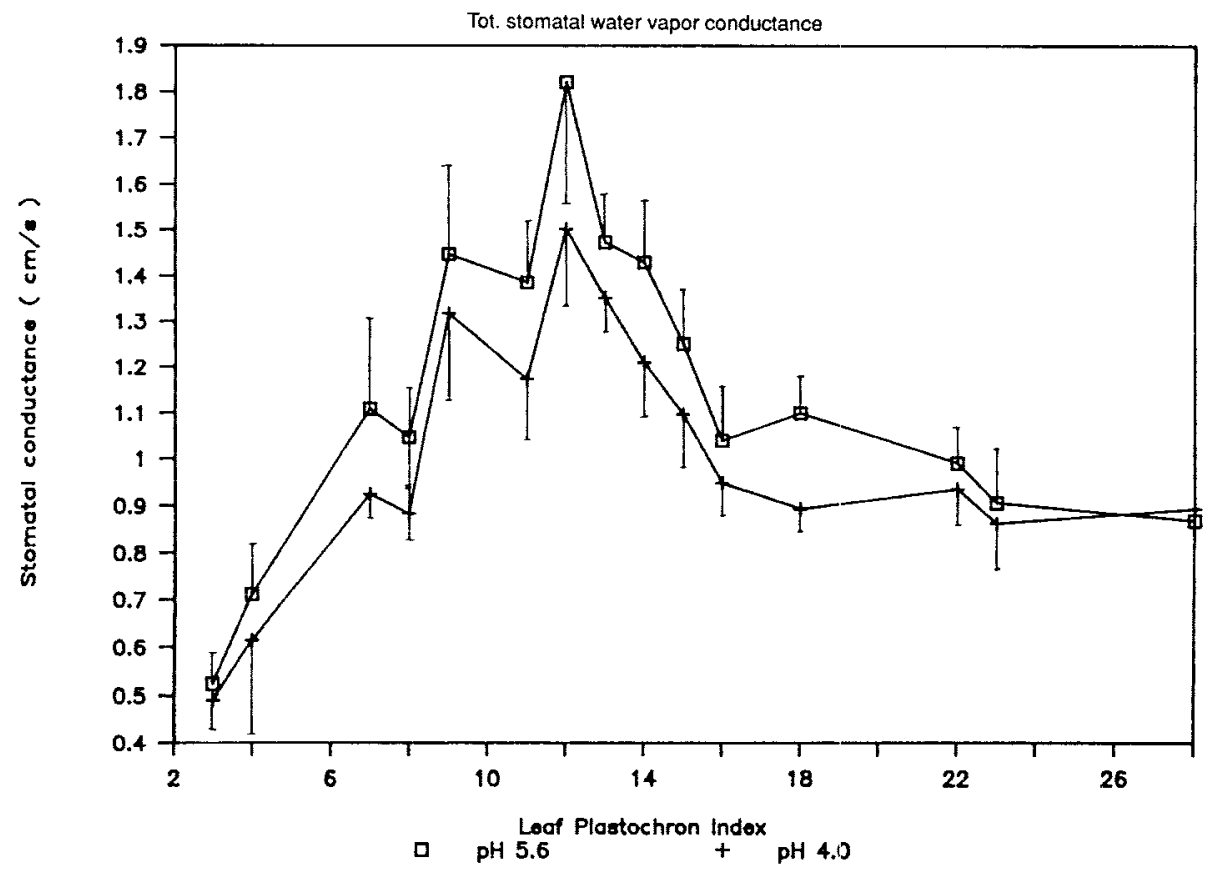

Fig. 2. Stomatal conductance, $g_{s}$ sat, at different leal ages (LPI) for both $\mathrm{pH}$ groups. Bar: $95 \%$ confidence limit. 
surements of upper and lower leaf surfaces (Fig. 2). For both clones and treatments, $g_{\mathrm{s}}$ sat shows its maximal value on fully expanded leaves. The optimal leaf ages were LPI 9 for $\mathrm{cV}$. Beaupré and LPI 12 for cv. Robusta. On the whole, acid rain caused a decrease of stomatal conductance; $g_{\mathrm{s}}$ sat was reduced by $24.0 \%$ for $\mathrm{cv}$. Beaupré and by $15.4 \%$ for cv. Robusta.

\section{Discussion and Conclusions}

Both clones showed a decrease for $P N$ sat as well as for $g_{s}$ sat. Cultivar Beaupré was much more sensitive to acid rain treatment than cv. Robusta, as well for photosynthesis as for water vapor conductance. Effects of treatment were statistically significant $(P=0.05)$ for $\mathrm{cv}$. Beaupré, but not for cv. Robusta. Maximal sensitivity corresponded to maximal leaf gas exchange rates (optimal leaf ages).

\section{Acknowledgments}

This study was supported by the Instituut tot Aanmoediging van het Wetenschappelijk Onderzoek in Nijverheid en Landbouw (Brussels, Belgium).

\section{References}

Ceulemans R., Kockelbergh F. \& Impens I. (1986) A fast, low cost and low power requiring device for improving closed loop $\mathrm{CO}_{2}$-measuring systems. J. Exp. Bot. 37, 1234-1244

Freer-Smith P.H. (1984) The responses of six broadleaved trees during long-term exposure to $\mathrm{SO}_{2}$ and $\mathrm{NO}_{2}$. New Phytol. 97, 49-61

Steenackers $V$. (1982) Selectie van populieren voor biomassaproduktie. In: Produktie van biomassa, notities t.a.v. studiedag KI-VIV op 7 november 1982 in Bokrijk-Genk

Wang D., Karnosky D.F. \& Bormann F.H. (1986) Effects of ambient ozone on the productivity of Populus tremuloides Michx. grown under field conditions. Can. J. For. Res. 16, 4755 